\title{
EL PROBLEMA DE LAS ÉPOCAS LITERARIAS EN JUAN RAMÓN JIMÉNEZ
}

\section{ÉPOCAS Y ESTILOS}

En la extendida producción de Juan Ramón Jiménez hay, como sabemos, una vuelta constante del autor sobre sus poemas anteriores para lograr, a partir de cierto momento, una expresión más depurada, particularidad que llegó a convertirse en un signo distintivo de su obra. No se trata, por supuesto, de un rasgo exclusivo, pero como no abundan los buenos ejemplos en lengua española, el de Juan Ramón Jiménez es poco menos que ineludible en las consideraciones sobre el tema.

Asimismo, y de manera paralela, es explicable que un itinerario poético como el suyo, que atraviesa prácticamente 60 años, ofrezca diversas etapas, épocas o cambios de estilo. Increíble hubiera sido, en un lapso tan prolongado y con una producción tan nutrida como la que ostenta, una complexión monolítica. No, lo que nos muestra Juan Ramón Jiménez (como muchos otros) es la persecución de nuevos caminos. Aciertos ocasionales, logros debidos a ecos pasajeros o de reflejo, no suelen determinar, pasado el momento, igual satisfacción o complacencia. Por el contrario, es corriente la pugna entre lo que el poeta ha realizado y lo que, ambiciosamente, aspira a conseguir. Es difícil pretender uniformidad de los autores en esta dirección, y lo único que cabe afirmar es que Juan Ramón Jiménez es buen motivo para estudiar esta actitud. Y como aquí no hay mayores dudas, creo que vale la cita del propio autor, ya hacia el final de su vida. Así, escribió en el "Prólogo" a Un libro escojido, de 1954, a manera de resumen y conclusión: ". . . mi biografía es empezar siempre; mi bibliografía siempre empezar..."'1.

1 Véase Juan Ramón Jiménez, Selección de cartas (1899-1958), Picazo, Barcelona, 1973, p. 355. 
Lo que podemos agregar es que difícilmente, ni aun los grandes poetas ( $y$, sobre todo, aquellos que han dejado una producción abundante) dan ya en sus primeras obras su nivel más alto y personal. Y esto, sí, tiene apariencia de "ley".

Para no apartarnos demasiado de Juan Ramón Jiménez, recurro al breve cotejo entre éste y dos poetas cercanos, que tienen además ciertas semejanzas (particularmente iniciales) con el poeta de Moguer. Me refiero a Manuel Machado y Francisco Villaespesa. Pues bien, creo que no es forzado aceptar que tanto Manuel Machado como Villaespesa alcanzan ya, tempranamente, su “"estilo" y hasta sus mejores obras. El caso de Machado es harto conocido: Alma, de 1900 (primera obra sin colaboración ajena), nos ofrece no sólo los rasgos fundamentales de su poesía sino también su mejor libro. Y como decía Alfredo Carballo Picazo en un sustancioso prólogo, Alma presenta acabadamente los elementos esenciales de toda la poesía posterior de Manuel Machado². Sin olvidar, claro, que su obra posterior es casi tan numerosa como la de Juan Ramón Jiménez. Lo que es mucho decir. Algo parecido podemos afirmar de Francisco Villaespesa, tanto en la especial cronología (y prioridades) como en lo copioso de la obra ${ }^{3}$.

De tal manera - y sin pretender más que una comparación determinada por la cercanía - cabe agregar de inmediato que la producción de Juan Ramón Jiménez supera ostensiblemente leves semejanzas externas y, por el contrario, es más lo que se diferencia que lo que se asemeja. A su vez, debo decir que quizás los ejemplos de Manuel Machado y Villaespesa no correspondan a los casos más típicos. Es más corriente que la culminación, o culminaciones, se alcancen después de una trayectoria con cierto paralelismo biológico, nunca exagerado. No cambia el respaldo que suele aportar la abundancia, y que es válido para los tres autores, si bien -insisto- el que parece cumplir mejor con la "ley", a que me referí es, sin duda, Juan Ramón Jiménez.

Hablar de las etapas o ciclos en la lírica del poeta de Moguer es replantear uno de los tópicos insoslayables vinculados a su nombre y su obra. Con la aclaración de que nuestro autor dejó, aquí, un material de poco común caudal. Además, dejó también (cosa típica en él) una serie igualmente nutrida de comentarios y auto-

${ }^{2}$ Cf. Manuel Machado, Alma. Apolo, Eds. Alcalá, Madrid, 1967, pp. 5-137.

${ }^{3}$ Cf. Francisco Villaespesa, Poesias completas, ed., pról. y notas de Federico de Mendizábal, Aguilar, Madrid, 1954, t. 1. 
críticas. Y, como si eso fuera poco, nos dejó asimismo un poema que, situado cronológicamente hacia el centro de su bibliografía, ha sido visto por muchos de sus críticos como una especie de clave, y referencia ineludible siempre que se plantea este problema de sus etapas líricas. De más está decir que ese poema no es otro que el que comienza: "Vino, primero, pura..."'4. Poema que - espero mostrarlo- aparece, en esta dirección, más llamativo que positivo. O, mejor, más logrado como "poesía" que como "testimonio". Aunque mi explicación resulte abundante, diré que Juan Ramón Jiménez nos da en esa famosa pieza lírica una visión de la "mujer" (y sus vestidos o adornos) en diferentes momentos de la vida del poeta. "Mujer"' que, hacia el final, el autor identifica con la poesía. De ahí la distinción en las tres (o cuatro) etapas, aceptadas no sólo como identificadas con la poesía, sino, en especial, con su poesía.

Aunque no siempre resulta convincente el paralelismo ("alegoría" podríamos llamarla con mayor exactitud), tiene ya valor de lugar común esta traducción, que atiende sobre todo a tres etapas cronológicas:

1) El comienzo (de "pureza" intuitiva).

2) El momento modernista (o de enriquecimiento exterior).

3) El momento de plenitud (o de la "pureza" consciente, de la poesía "esencial", etcétera).

En razón directa de su rotunda eficacia lírica, poco tardó en aceptarse esta partición como una verdad total, y así fue frecuentemente glosada por la crítica. No fue - acepto- una ratificación ciega, pero sí hubo mucho de fervor "mítico", por el hecho de concederse valor de inventario a las palabras del poeta. Que pudo o no darle dicho valor. Y que si se lo dio, no excluye, de nuestra parte, la libertad de disentir...

Ésta es, con gran ventaja, la "declaración" más difundida de Juan Ramón Jiménez vinculada a sus etapas o ciclos poéticos. Pero bien sabemos que, si no tan conocidas, nos dejó otras manifestaciones similares, en verso o en prosa, y de más o menos decoroso perfil. Con el agregado de que, posteriores, permiten también variantes o diferencias con el poema de Eternidades. Repito: éste, sí, el más famoso...

No es un poema, aunque tuvo bastante difusión, la "Síntesis ideal" que incluyó la primera edición de la Poesía española [contem-

4 Véase Juan Ramón JimÉnez, Segunda antolojía poética (1898-1918), Espasa-Calpe, Madrid, 1922, p. 276. 
poránea] publicada por Gerardo Diego en 1932. Hay que aclarar que allí figura también un Esquema autobiográfico con algunos puntos de contacto con la Sintesis ideal. Como sabemos, la variante principal está en el notable crecimiento, superior a lo que muestra su poesía, que casi duplica las etapas a cinco (o seis). Y no reparamos aquí en el estribillo de la "soledad" 5 .

Con posterioridad, y en forma paralela a una producción lírica que no baja su número, insistió Juan Ramón Jiménez, a veces hasta con singular dramatismo, en el problema de sus épocas literarias. Vemos así repetirse el cuadro de las cinco (o seis) épocas o ciclos, pero también asoman clasificaciones de dos, tres, cuatro... ${ }^{6}$

La conclusión a que llegamos es que el itinerario que va marcando Juan Ramón Jiménez a través de los años no se caracteriza

${ }^{5}$ Cf. Gerardo Diego, Poesía española. Antología (1915-1931), Signo, Madrid, 1932. Véase la ed. posterior, con noticias de Gerardo Diego acerca del retiro de Juan Ramón Jiménez de la antología (Poesía española contemporánea, 1901-1934, Taurus, Madrid, 1959, pp. 607-609). No interesan aquí las otras modificaciones que sufrió esta obra. Copio, sí, la Síntesis ideal:

“1. Influencia de la mejor poesía eterna española, predominando el Romancero, Góngora y Bécquer. Soledad.

2. El Modernismo, con la influencia principal de Rubén Darío. Soledad.

3. Reacción brusca a una poesía profundamente española, nueva, natural y sobrenatural, con las conquistas formales del Modernismo. Soledad.

4. Influencias jenerales de toda la poesía moderna. Baja de Francia. Soledad.

5. Anhelo creciente de totalidad. Evolución creciente, seguida, responsable, de la personalidad íntima, fuera de escuelas y tendencias. Odio profundo a los ismos y los trucos. Soledad.

6. y siempre. Angustia dominadora de eternidad. Soledad" (Ibid. p. 609).

${ }^{6}$ Siguiendo un orden más o menos cronológico, menciono los siguientes testimonios:

[1944] "Aunque yo distingo en mi poesía cinco ciclos bien distintos, es una unidad - como que mi vida ha sido una función poética- y yo quisiera verla, no en libros, que siempre son sucesivos y crean la perspectiva de un pasado, sino presente y simultánea como un cielo estrellado..." (Declaraciones a Enrique Anderson Imbert. Véase E. ANDERSON IMBERT, "Juan Ramón Jiménez: entrevista y coda" [1944], en Los grandes libros de Occidente y otros ensayos, De Andrea, México, 1957, p. 254).

[1945] "Usted ha visto que yo no era el mismo de mis primeros tiempos con traje nuevo. Mi cambio desde el Diario fue de fondo y forma, y no me lo trajo ningún motivo literario sino un primer viaje largo por mar. Es claro que no se puede nunca cambiar del todo ni hay 
ciertamente por su coherencia o rigor, porque, si por un lado da a entender ampliaciones e incorporaciones, muestra también, por otro, repliegues y contradicciones. De lo que sí nos convence, aunque no sea en él novedad, es de su preocupación constante por el fenómeno de la poesía. Que, por supuesto, llega a identificarse a menudo con el fenómeno de su poesía.

La crítica, particularmente aquella que podemos llamar "reverencial", ha acogido con frecuencia la autocrítica de Juan Ramón Jiménez y, sobre todo en el caso de lo que éste "declara" en el poema "Vino, primero, pura...", con una rotundidad que, me parece, resulta exagerada. Repito una vez más que no se trata de aceptar o negar en bloque lo que un autor opine acerca de su obra, sino de aquilatar, como corresponde, su obra más que sus juicios.

Comparativamente, concedo más valor (aunque, como veremos, cuesta alejarse de ciertas seducciones) a críticas como las de Enrique Díez-Canedo, Rachel Frank y, sobre todo, Emmy Neddermann. Así, según Díez-Canedo, hay tres etapas cronológicas (o "maneras") dentro de la lírica del poeta de Moguer, división que el crítico enuncia hacia 1944: 1) la manera sentimental, que ve en los primeros libros, con preferencia en el verso del romance; 2) la manera pictórica, en libros posteriores, con preferencia por el alejandrino modernista, y 3) la manera sintética, de poesía desnuda, con preferencia por el verso breve ${ }^{7}$.

No importa que una vez más, hacia 1953, Rachel Frank recuerde, como si fuera una cita fija o ineludible, el famoso poema

por qué volverse del todo contra el simbolismo francés, que era tan español..." (J.R.J., carta a Guillermo de Torre, fechada el 2 de junio de 1945. Véase Selección de cartas, p. 281).

[1949] En la primera edición de Animal de fondo, Juan Ramón Jiménez traza, otra vez, su itinerario lírico. Y con una variante acorde a la importancia del libro, nos habla de tres épocas que, en realidad, son cuatro: 1) hasta 1909-1910; 2) hasta 1921-1922; 3) hasta 1949; 4) interpretamos que se abre con Animal de fondo. Dios deseante y deseado. (Véase "Notas" a la primera edición. Texto bilingüe, con la versión francesa de Lysandro Z. D. Galtier, Buenos Aires, 1949).

[1953] "Ninguna de las dos selecciones me gusta, porque no ha equilibrado bien lo que la crítica suele llamar mis tres épocas..." (Se refiere J.R.J. a las publicadas en la revista Poetry, de Chicago, y en la antología de J.B. Trend, aparecida en Oxford. Carta a Astrid Mercedes Ness, en Selección de cartas, p. 301).

${ }^{7}$ Enrique Dízz-CANedo, Juan Ramón Jiménez en su obra, El Colegio de México, México, 1944. 
"Vino, primero, pura... ". Más importancia le asignó a su posterior, y personal, clasificación de las que llama "las tres fases" de Juan Ramón Jiménez: 1) la fase intuitiva; 2) la fase de enriquecimiento, y 3) la fase conscientemente simplificada ${ }^{8}$.

En fin, aunque sea necesario retroceder en el tiempo, no podemos olvidar las aún útiles reflexiones de Emmy Neddermann sobre el poeta andaluz, estampadas en su libro de 1935. En ella encontramos también tres etapas, que enuncia de la siguiente manera: 1) subordinación del mundo exterior al yo (poesía del poeta ensimismado); 2) identificación panteísta del yo (de sensibilidad más receptiva), y 3) fusión mística del yo con la naturaleza ${ }^{9}$.

¿A qué solución llegamos? Yo creo que, sin la ingenua pretensión de poner punto final a este transitado tópico de las "épocas” o ciclos de Juan Ramón Jiménez, me decido, finalmente, por la más escueta partición en dos etapas. Partición, en última instancia, no alejada de la que en cierto momento (1945) propuso el propio poeta, urgido por la brevedad. Tampoco alejada de clasificaciones como la de Emmy Neddermann, ya citada. Y, en especial, si bien tampoco pretendo exclusividad en el procedimiento, porque mi punto de partida no es otra cosa que el reconocimiento de la materia básica. Es decir, una trayectoria lírica, y no una trayectoria de la autocrítica de Juan Ramón Jiménez. En fin, si no es demasiada pretensión de mi parte, alejada tanto de su cambiante fijación de "épocas", como, en otro nivel, del también declarado intento del poeta de una poesía "unificada" en un ulterior trabajo de corrección y taracea.

Sobre esta base, creo que ya las palabras sobran y es urgente decir algo más concreto. He aquí las dos etapas que propongo:

1) Etapa de crecimiento y afinación. De la naturaleza exterior, de la identificación entre paisaje y sentimiento, de la vida y la muerte, y el panteísmo. De la ornamentación, y las correspondencias pictórico-musicales (modernismo y postmodernismo).

2) Etapa de plenitud, y de la desnudez expresiva. De la poesía sobre el arte y la poesía, y de ramificaciones metafísico-religiosas. En fin, de la "religión de la conciencia" (expresionismo).

${ }^{8}$ Cf. Rachel Frank, "Juan Ramón Jiménez: the landscape of the soul", Poetry, Chicago, 83 (1953), p. 231.

${ }^{9}$ Emmy Neddermann, Die Symbolistischen Stilelemente im Werke von Juan Ramon Jimenez, Hamburg, 1935. Noticias extraídas de RAIMUNDO LIDA, "Sobre el estilo de Juan Ramón Jiménez”' en Letras hispánicas. Estudios, esquemas, F.C.E., México, 1958, pp. 173-175; y Rachel FranK, art. cit., pp. 231-232. 
Como vemos, se elimina aquí (o, por lo menos, no se le concede lugar especial) el momento de comienzos del poeta, al cual muchos críticos han concedido más importancia de la que merece. En especial, a caballo de su famoso poema. Y esto - agrego- no va en desmedro de la categoría alcanzada posteriormente por Juan Ramón Jiménez, como no va en desmedro de ningún autor de relieve su momento de iniciación, raramente genial . . En lo que se refiere al lapso que separa las etapas, creo que podemos fijarlo, con intencionada vaguedad, hacia 1914-1915.

Volviendo al momento inicial de Juan Ramón Jiménez, me parece que una breve comparación ilustra sobre estos excesos de perspectiva. Como se trata, en su caso, de un autor de producción abundante, vale aquí, por lo menos, el cotejo con otro famoso autor, si no tan fecundo, de producción nutrida. Y este autor no es otro que Rubén Darío. Pues bien, ¿quién recuerda hoy las obras iniciales del poeta nicaragüense? Algún valor tienen, claro, pero poco dicen en relación con su obra posterior. Y las obras primerizas de Juan Ramón Jiménez no superan ese relieve comparativo, aún más diluido por el número de su obra total.

\section{Primera ÉPOCA}

Entre infinidad de ejemplos, elijo un poema del libro Laberinto, publicado en 1913. Por la fecha pareciera acercarse al segundo momento, pero no creo que haya mayores dudas con respecto a su real ubicación, que es ésta que le asigno. Copio:

Por los espejos se idealiza la mañana en una alegría distante y solitaria... La fronda es más de ensueño, el oro es más de plata, el amor más sereno, las voces más fantásticas.

Se daría la vida por un beso; las alas se abren más frescas, más luminosas, más blandas, resplandece la frente tersa, maravillada, el corazón, como una alondra, ríe y canta.

Cual una barca májica boga la tibia estancia, pasan en ronda dulce, rosas blancas y granas, y en el rayo de sol, que entra irisado, vaga no sé qué intacto y mate traje de desposada... ${ }^{10}$

10 “Mañana nupcial" en Laberinto, Renacimiento, Madrid, 1913, pp. 3334 (Laberinto incluye composiciones que corresponden a los años 1910-1911). 
En los alejandrinos del poema (claras reminiscencias aparte) notamos, en primer lugar, el rotundo predominio sonoro que aporta sobre todo la presencia de la rima $a-a$, a lo largo de todo el texto. $Y$, no casualmente, un intento de fusión temático sonoro, en primer término, y temático plástico, en segundo lugar (vestido de desposada, espejos, oro, plata, sol, rosas, barca). Abundancia de adjetivos cromáticos y no cromáticos, e imágenes. El término de comparación más subraya, con su nota intensificadora, el poema que, finalmente, remata con una intencionada, acumulada sensación de vaguedad...

\title{
TRANSICIÓN
}

Con el deseo de mostrar que, efectivamente, cabe dentro de la poesía de Juan Ramón Jiménez el reconocimiento de composiciones que indican un periodo de transición, me detengo brevemente en este punto. Insisto una vez más en que tal posibilidad resulta bien explicable, aunque a veces los ejemplos más nítidos parezcan diluirse dentro de su abundancia. En fin, creo que un corto poema puede servirnos para ver cómo se va preparando en Juan Ramón Jiménez, sin mayor urgencia, el nuevo momento. La perspectiva con que contamos nos permite captar los pasos que median entre la insistencia de temas y formas expresivas anteriores, y las nuevas direcciones que se anuncian. He aquí el poema, extraído de su libro Estío (obra de 1915, publicada en 1916):

\author{
A un niño \\ muerto en un cuadro \\ Sí, me pareces, muerto, \\ un paisaje sin cielo. \\ No. Un paisaje nevado, \\ con el cielo más alto ${ }^{11}$.
}

11 Juan Ramón Jiménez, Estió, Calleja, Madrid, 1916, p. 30. Tanto o más firme es el paso que descubrimos en la rica prosa poemática de Juan Ramón Jiménez. En primer lugar, el previsible ejemplo de Platero y yo: "Platero es pequeño, peludo, suave; tan blando por fuera, que se diría todo de algodón, que no lleva huesos. Sólo los espejos de azabache de sus ojos son duros cual dos escarabajos de cristal negro... " ¿A qué seguir? Si son párrafos que todos conocemos de memoria.. Quizás por eso convenga mejor recordar la prosa poemática, menos conocida, de un libro algo posterior, en que se alternan prosa y verso. Eso sí, también obra ineludible en la mejor bibliografía de nuestro 
Poema, entre muchos, donde aún persisten, sobre todo, temas inconfundibles de su primera etapa, si bien encarados ya con estructuras, rasgos expresivos y hasta el poder de síntesis que identificamos, mejor, con el Juan Ramón Jiménez posterior.

\section{SEgunda ÉPOCA}

Llegamos, obligadamente, al momento de plenitud en la obra de Juan Ramón Jiménez, sin que tal reconocimiento -es obviosignifique borrar los logros de su época anterior. Pero no hay ninguna duda de que es esta etapa la que identificamos como de personalización y culminación del poeta. Momento al cual corresponde, como ganado título, el nombre de época de la "desnudez expresiva", aunque de inmediato un nombre tan escueto obligue a hacer aclaraciones y agregados.

Ya sabemos cómo Juan Ramón Jiménez llega a esta instancia: lo hace a través de una copiosa obra donde resulta patente una búsqueda signada por la insatisfacción. Insatisfacción donde se subraya también, a partir de un momento dado, la constante revisión y la "corrección". Sin ir muy lejos, la noción de "desnudez" ya nos enfrenta con variantes que no podemos soslayar. Hay una desnudez que aceptamos como natural (o más natural) y una desnudez que vemos como producto de la elaboración consciente. No es necesario pensar mucho para situar a Juan Ramón Jiménez en este último tipo.

Siguiendo con las notas que contribuyen a perfilar esta característica de su poesía, diré que también tienden a individualizarla el predominio de las oraciones principales, la escasez o ausencia de metáforas y de otros tropos (pero no de imágenes), la parquedad en el uso de los nombres propios ${ }^{12}$, la escasez de adjetivos

autor: "La negra va dormida, con una rosa blanca en la mano. - La rosa y el sueño apartan en una superposición mágica, todo el triste atavio de la muchacha: las medias rosas caladas, la blusa verde y trasparente, el sombrero de paja de oro con amapolas moradas - Indefensa con el sueño, se sonríe, la rosa blanca en la mano negra"; "La negra y la rosa"' (dedicado a Pedro Henríquez Ureña) en Diario de un poeta recién casado, Calleja, Madrid, 1917, p. 107. (Cursivas en el original.)

${ }^{12}$ Una de las señales indirectas que toma la desnudez en J.R.J. debemos verla en la escasez o ausencia de nombres propios en su poesía. Y esto no sólo como característica de su etapa de culminación. A su vez, la particularidad puede extenderse a los títulos. Sólo alguna obra (como ocurre con el Diario...) parece alterar este signo. Debemos interpretar que, sin alcanzar allí un núme- 
(particularmente, los cromáticos) ${ }^{13}$, o su selección, y aparte de eso, la abundancia de símbolos.

En otro nivel, una métrica limitada al romance, a formas de la "canción" y al verso blanco (a veces, Juan Ramón Jiménez, como otros, llama "verso libre" al verso blanco) ${ }^{14}$. En fin, como ya lo deja entender este esquema, preferencia por el verso octosílabo y, menes, por la rima asonante (cuando usa la rima). Repudio de la rima consonante. . Además, notoria interrelación entre verso y prosa poemática. Igualmente, alternancia entre juegos sonoros de las palabras y los signos tipográficos, más perceptibles aún, dentro del plano visual, en la grafía (eso sí, poco compleja) de Juan Ramón Jiménez.

La insistencia en la nota identificadora de la "desnudez" no debe hacernos perder de vista que es, comprensivamente, relativa. Que se impone, sobre todo, por lo que significan otros ejemplos, especialmente contemporáneos, dentro de la lírica. Pero es justo señalar (como ocurría en el caso, harto conocido, de Bécquer) que en la lengua poética de Juan Ramón Jiménez no desaparecen repeticiones, paralelismos, anáforas, antítesis, ni oraciones explicativas entre guiones... Clara señal de una supervivencia que si aparentemente ligamos a una retórica, verdad es también que no pueden catalogarse ni como recursos complejos ni como alardes. Por el contrario, su propia sencillez o "facilidad" no deja de contribuir (como sabemos, hay retóricas y retóricas) a esa sensación de desnudez que procuro desentrañar. En conclusión, des-

ro excesivo, la mayor frecuencił obedece, en buena parte, a los temas que registra dicho poemario. Como contraste, recuerdo que Henry Bremond destacaba, en poetas como Béranger y Hugo, su abundancia. Así, decía de Víctor Hugo: " . . . et comme tant de vers sonores du père Hugo, qui ne contiennent rigoureusement que des noms propres..." (H. BREMOND, La poésie pure, B. Grasset, Paris, 1926, p. 62. Véanse también pp. 19-20).

${ }^{13}$ Insisto en que los adjetivos cromáticos se van haciendo más escasos al avanzar la producción de Juan Ramón Jiménez. No aún, como hemos tenido ocasión de ver, en obras como Diario de un poeta recién casado. Como sabemos, el poeta cambió posteriormente el título del libro: Diario de poeta y mar. (Véase ed. de A. Aguado, Madrid, 1957.)

14 ["Verso desnudo"']: "Este verso es el que yo llamo desnudo y en el que empecé a escribir decididamente desde el año 1916, Diario de un poeta. Y desde entonces no me gustan más versos españoles que el octosílabo del romance mío, el apropiado de la canción y el verso libre, digo desnudo. El consonante lo aborrezco hoy y creo que nos quita nuestra poesía para darnos la suya. Nos hace esclavos..." (J.R.J., carta a Ángela Figuera Aymerich, fechada en Riverdale, Maryland, el 3 de noviembre de 1949. Véase Selección de cartas [18991958], p. 226). 
nudez que equivale, en mucho, a sencillez elaborada, a trabajo consciente de depuración ${ }^{15}$.

Veamos ahora algunos ejemplos, ya afirmado el poeta en la que consideramos segunda etapa, si bien no hay necesidad de alejarse mucho de un punto de partida visible. Escojo, así, tres breves poemas que pertenecen a Eternidades y a Piedra y cielo. Y dejo fuera, exprofeso, poemas muy conocidos ("No sé con qué decirlo”, “Intelijencia, dame”, “ ¡Palabra mía eterna!...”, etc.).

El dormir es como un puente que va del hoy al mañana.

Por debajo, como un sueño, pasa el agua ${ }^{16}$.

Yo no soy yo.

Soy este

que va a mi lado sin yo verlo, que, a veces, voy a ver, y que, a veces, olvido.

El que calla, sereno, cuando hablo, el que perdona, dulce, cuando odio, el que pasea por donde no estoy, el que quedará en pie cuando yo muera ${ }^{17}$.

Por último, el poema de Piedra y cielo con el que, no casualmente, Juan Ramón Jiménez clausuró su recordada Segunda antolojía poética:

Quisiera que mi libro

fuese, como es el cielo por la noche, toda verdad presente, sin historia.

Que, como él, se diera en cada instante, todo, con todas sus estrellas; sin que niñez, juventud, vejez quitaran ni pusieran encanto a su hermosura inmensa. ¡Temblor, relumbre, música presentes y totales!

${ }^{15} \mathrm{Y}$ ya que toco algunos conceptos caros al poeta, diré que no estoy muy de acuerdo (como muestro más detalladamente en otro lugar) con sus reflexiones acerca de la espontaneidad y la perfección (aun dentro de la dimensión humana con que podemos aceptar la perfección).

16 "Eternidades» en Segunda antolojía poética (1898-1918), Espasa-Calpe, Madrid, 1920, p. 278.

${ }^{17}$ Ibid., p. 388. 
¡Temblor, relumbre, música en la frente

- cielo del corazón- del libro puro! ${ }^{18}$

DOS ÉPOCAS, DOS POEMAS

Como variante, dentro de una misma concepción, ensayo ahora una nueva perspectiva con ejemplos orientadores. Verdad es que resulta difícil pretender, a través de dos poemas y en rápido cotejo, una visión nítida de las dos épocas de Juan Ramón Jiménez, por lo pronto, de las dos épocas que yo defiendo. Por eso, admitiendo la dificultad, más aún si tenemos presente el extendido caudal lírico del poeta, y presentando yo el enfoque como variante en relación con los testimonios ya examinados, es posible que se justifique el ejemplo especial que ahora propongo.

Trato, simplemente, de tentar una comparación entre dos poemas de Juan Ramón Jiménez que ofrecen cierta cercanía temática: un conocido poema de los Sonetos espirituales (1914-1915) y una aún más breve poesía incluida en Eternidades (1916-1917).

En primer lugar, llama la atención la proximidad cronológica de las dos obras, quiero decir, de los dos poemas. Como se verá, el primero es mucho más conocido que el segundo. Pero aquí se trata menos de establecer un cotejo de valor (por otra parte, poco aconsejable en un mismo poeta) que de reflejar, insisto, las etapas líricas de Juan Ramón Jiménez. Eso sí, no creo que haga falta aclarar que la proximidad temática a que me refiero es sólo un elemento dentro de la más compleja elaboración y concepción que determinan los poemas.

El soneto es el titulado "Octubre" (uno de los varios "Octubre" que escribió) y figura, como he dicho, en los Sonetos espirituales. A través de esta colección entramos ya, cronológicamente, en su época de cambio, tal como lo revelan diferentes testimonios. Sin olvidar, entre ellos, la prosa poemática de Platero y yo. Sin embargo, no se ve eso - pienso- en los Sonetos, que, comenzando por su especial e inconfundible forma métrica, pertenecen claramente a la primera etapa. El soneto "Octubre" figura en infinidad de antologías, y sólo razones de precisión me obligan a copiarlo: 


\section{Octubre}

Estaba echado yo en la tierra, enfrente del infinito campo de Castilla, que el otoño envolvía en la amarilla dulzura de su claro sol poniente.

Lento el arado, paralelamente abría el haza oscura, y la sencilla mano abierta dejaba la semilla en su entraña partida honradamente.

Pensé arrancarme el corazón, y echarlo, pleno de su sentir alto y profundo, al ancho surco del terruño tierno;

a ver si con romperlo y con sembrarlo, la primavera le mostraba al mundo el árbol puro del amor eterno ${ }^{19}$.

Y ésta es la breve composición incluida en Eternidades, y que incluimos también como ejemplo de la segunda época del poeta:

Estoy soñando, echado

a tu sombra, en tu tronco suave...

$\mathrm{Y}$ me parece

que el cielo, copa tuya, mece su azul sobre mi alma ${ }^{20}$.

En el soneto asistimos a la particular estructura que configuran, siguiendo el molde tradicional, los cuartetos (el mundo exterior, espacio y tiempo) y los tercetos (con explicable enlace, el mundo exterior del poeta). El tema se resuelve en un encadenamiento paralelo de símbolos, dispuesto en tres planos:

$$
\begin{aligned}
& \text { otoño-primavera } \\
& \text { siembra-árbol (y fruto) } \\
& \text { corazón-amor }
\end{aligned}
$$

El sentido panteísta del soneto es evidente. Por otra parte, tal como señalé, las implicaciones que derivan de la forma de soneto. La contraposición (y, al mismo tiempo, enlace) entre el mun-

${ }^{19}$ Ibid., p. 232.

${ }^{20}$ Ibid., p. 281. 
do exterior e interior, la importancia de la anécdota. En otro nivel, los paralelismos, la abundancia de adjetivos.

El breve poema "Estoy soñando, echado" presenta, como es fácil notar, alguna leve semejanza con el soneto. De manera mucho más concentrada, aparecen aquí también el poeta y el símbolo del árbol. Pero son dos poemas distintos. La comprimida extensión no impide que se agregue un segundo personaje, representado por la vaga presencia de la amada (amada que, en última instancia y para ser fiel a Juan Ramón Jiménez, cabe igualmente identificar con la Poesía).

Hay dos planos notorios, que enunciamos así:

1) Poeta (y sueño) / amada (y árbol). La sombra como enlace.

2) Amada (y cielo) / poeta. Ascenso del poeta a la Belleza.

La métrica del poema y su verso blanco nos sitúan -compresiones aparte - en un ámbito muy distinto al que marcaba la simetría del soneto. El predominio casi absoluto de formas verbales y nominales, algún disimulado adjetivo, la ausencia de imágenes y metáforas, dejan sólo, como presencias de la lengua poética, el resaltante valor de los símbolos y de la hipérbole "copa de árbol / cielo"'.

En fin, creo que el breve poema de Eternidades, si no puede mostrarse como ejemplo de alta poesía, sirve por lo menos, y dentro del pie dado por otro poema de Juan Ramón Jiménez, para ejemplificar que, en efecto, la desnudez es rasgo fundamental de esta etapa de su poesía. Y, como agregado un tanto redundante, que el signo de la desnudez tiene sin duda más consistencia, para penetrar en ella, que el discutible concepto de la pureza. 